\title{
Article
}

\section{Gbaud On-Off Keying/Pulse Amplitude Modulation Links in C-Band for Short-Reach Optical Interconnects}

\author{
Oskars Ozolins ${ }^{1,2,3, * \mathbb{D}}$, Xiaodan Pang ${ }^{2} \mathbb{D}$, Aleksejs Udalcovs ${ }^{1} \mathbb{D}$, Richard Schatz ${ }^{2} \mathbb{D}$, Sandis Spolitis ${ }^{3,4} \mathbf{D}^{\mathbb{D}}$, \\ Vjaceslavs Bobrovs ${ }^{3} \mathbb{D}$, Gunnar Jacobsen ${ }^{1}$ and Sergei Popov ${ }^{2}$
}

1 Networks Unit, RISE Research Institutes of Sweden, 16440 Kista, Sweden; aleksejs.udalcovs@ri.se (A.U.); gjacobsen1952@gmail.com (G.J.)

2 Applied Physics Department, KTH Royal Institute of Technology, 10691 Stockholm, Sweden; xiaodan@kth.se (X.P.); rschatz@kth.se (R.S.); sergeip@kth.se (S.P.)

3 Institute of Telecommunications, Riga Technical University, 1048 Riga, Latvia; sandis.spolitis@rtu.lv (S.S.); vjaceslavs.bobrovs@rtu.lv (V.B.)

4 Communication Technologies Research Center, Riga Technical University, 1048 Riga, Latvia

* Correspondence: oskars.ozolins@ri.se or ozolins@kth.se or oskars.ozolins@rtu.lv; Tel.: +37-120-011-193

check for

updates

Citation: Ozolins, O.; Pang, X.; Udalcovs, A.; Schatz, R.; Spolitis, S.; Bobrovs, V.; Jacobsen, G.; Popov, S. 100 Gbaud On-Off Keying/Pulse Amplitude Modulation Links in C-Band for Short-Reach Optical Interconnects. Appl. Sci. 2021, 11, 4284. https://doi.org/10.3390/ app11094284

Academic Editor: Giuseppe Rizzelli

Received: 19 March 2021

Accepted: 5 May 2021

Published: 9 May 2021

Publisher's Note: MDPI stays neutral with regard to jurisdictional claims in published maps and institutional affiliations.

Copyright: (c) 2021 by the authors. Licensee MDPI, Basel, Switzerland. This article is an open access article distributed under the terms and conditions of the Creative Commons Attribution (CC BY) license (https:/ / creativecommons.org/licenses/by/ $4.0 /)$.

\begin{abstract}
We experimentally evaluate the high-speed on-off keying (OOK) and four-level pulse amplitude modulation (PAM4) transmitter's performance in C-band for short-reach optical interconnects. We demonstrate up to 100 Gbaud OOK and PAM4 transmission over a $400 \mathrm{~m}$ standard single-mode fiber with a monolithically integrated externally modulated laser (EML) having $100 \mathrm{GHz}$ $3 \mathrm{~dB}$ bandwidth with $2 \mathrm{~dB}$ ripple. We evaluate its capabilities to enable $800 \mathrm{GbE}$ client-side links based on eight, and even four, optical lanes for optical interconnect applications. We study the equalizer's complexity when increasing the baud rate of PAM4 signals. Furthermore, we extend our work with numerical simulations showing the required received optical power (ROP) for a certain bit error rate (BER) for the different combinations of the effective number of bits (ENOB) and extinction ratio (ER) at the transmitter. We also show a possibility to achieve around $1 \mathrm{~km}$ dispersion uncompensated transmission with a simple decision feedback equalizer (DFE) for a 100 Gbaud OOK, PAM4, and eight-level PAM (PAM8) link having the received power penalty of around $1 \mathrm{~dB}$.
\end{abstract}

Keywords: optical interconnects; on-off keying; pulse amplitude modulation

\section{Introduction}

Datacenters experience enormous traffic growth due to the vast amount of data to be stored, transmitted, and processed [1-5]. This explosive growth of Internet Protocol (IP) traffic is driving datacenters to the so-called "Zettabyte Era". The Cisco Report predicts that annual global IP traffic will reach over 4.8 zettabytes/year by 2022 [5]. For some applications, such as those on Facebook, the internal traffic may be several orders of magnitude greater than external. In addition to the internal traffic required to build web pages and search indices, relatively recent machine learning (ML) applications are driving increasing amounts of both computation and traffic on the datacenter interconnection network [4]. Due to that, challenges arise to keep up the bandwidth scalability. The community is looking into cost-efficient short-reach optical interconnect for $800 \mathrm{GbE}$ intra-datacenter links [6]. We see solutions based on eight optical lanes thanks to compatibility with $400 \mathrm{GbE}$ building blocks [7]. Eight optical lanes-based $400 \mathrm{GbE}$ solutions are already being deployed [8,9]. Solutions based on eight optical lanes [10-15], or even four optical lanes [16-27], for $800 \mathrm{GbE}$ are more appealing thanks to the use of using high bandwidth components. This allows reducing of costs, power consumption, and complexity of parallelism.

The current industrial solution for $400 \mathrm{GbE}$ is based on four-level pulse amplitude modulation (PAM4) [8,9] instead of on-off keying (OOK) [19,28]. PAM4 reduces bandwidth requirements without excessive costs for sensitivity, digital signal processing (DSP), 
and transceiver complexity [29-32]. The higher spectral efficiency of advanced multilevel modulation formats, such as carrier-less amplitude and phase (CAP) or discrete multi-tone (DMT) modulations [33-36], can be beneficial to increase the bitrate of the single lane. However, we need to take into consideration the implementational complexity. Advanced modulation formats are also being extensively investigated to scale up the speed, even up to $1.6 \mathrm{TbE}[37,38]$. To gradually achieve this goal, we need to increase the baud rate of individual lanes even higher. In that manner, we can achieve the four optical lanes $800 \mathrm{GbE}$ solution. That requires broadband InP and/or silicon optoelectronic components with high phase and amplitude linearity [39-42]. Optical interconnects operating at 100 Gbaud and beyond per lane are needed. In this way, we can confront the growing bandwidth density and scalability issues in datacenters. We foresee that the industrial solution for codesigned and cointegrated electronics and photonics is around the corner. The required ultrahigh bandwidth building blocks are available: integrated circuits for generating PAM4 $[43,44]$ even without equalization [45]; modulators and photodetectors (PD) [17,39,46]; and analogue to digital converter (ADC) frontend for receivers [47]. We also need to mention that electronic instruments, such as arbitrary waveform generators (AWG) and digital storage oscilloscopes (DSO), have reached sampling rates beyond $200 \mathrm{GSa} / \mathrm{s}$ with plenty of bandwidth for 100 Gbaud signals. This will allow scaling bandwidth for intra-datacenter networks in a cost-efficient manner. The C-band enables proportional efficiency in bidirectional bandwidth for intra-datacenter links thanks to mature and efficient wavelength division multiplexing technology. However, the reach is limited in this band due to the chromatic dispersion (CD) imposing limitations for the system design. It is worth looking into the achievable system performance and reach with high baud rate to enable four optical lanes solutions for $800 \mathrm{GbE}$ links.

In this paper, we experimentally evaluate high-speed OOK and PAM4 transmitter performance in C-band for short-reach optical interconnect applications. Compared to our previous demonstrations $[18,20]$, we show detailed analysis on equalizer configurations and filtering for signals operating at up to 100 Gbaud. It is important to show the pros and the cons of the PAM4 generation scheme used to achieve this result. We characterize the performance using the externally modulated laser (EML) having $100 \mathrm{GHz} 3 \mathrm{~dB}$ bandwidth with a $2 \mathrm{~dB}$ ripple. Furthermore, we also include the results of numerical simulations. We study required received optical power (ROP) for a certain bit error rate (BER) for the different effective number of bits (ENOB) and extinction ratio (ER) at the transmitter. This allows estimating what implementation penalty to expect when designing high-speed transmitters. Besides, we also show achievable transmission reach in C-band for $100 \mathrm{Gbaud}$ OOK, PAM4, and eight-level PAM (PAM8) signals over standard single-mode fiber with a simple decision feedback equalizer (DFE). This paves the way for cost-effective short-reach optical interconnects with high-speed multilevel modulation formats. The remaining parts of the paper are organized as follows. In Section 2, the experiment setup is detailed, and corresponding results and discussion are presented. In Section 3, we show the simulation setup and results along with a discussion. The conclusions are drawn in Section 4.

\section{Experimental Setup and Results}

Figure 1a shows the experimental setup for evaluating the intra-datacenter link performance. First, we amplify and decorrelate two pseudorandom bit sequences with a word length of $2^{15}-1$ (PRBS15) at 40 Gbaud, 45 Gbaud, and 50 Gbaud. Then, we multiplex them in time domain using 2:1 selector [48] to form a single $80 \mathrm{Gbaud}, 90 \mathrm{Gbaud}$, and $100 \mathrm{Gbaud}$ nonreturn to zero (NRZ) sequences, respectively. In the case of OOK, we use one of the multiplexed outputs (as shown in Figure 1 with dashed line) at 100 Gbaud amplified in a $65 \mathrm{GHz}$ linear amplifier to drive the EML. In the case of PAM4, the attenuated signal is passively combined in an electrical $65 \mathrm{GHz}$ three-resistor combiner with an inverted decorrelated version. The generated PAM4 signal at electrical back-to-back (b2b) already has a penalty due to the nonequally spaced signal amplitude levels. This happens due to 
different losses in two paths of OOK signals that do not allow to achieve a precise $6 \mathrm{~dB}$ difference, since the decorrelation suffers from technical implementation limitations.

(a)
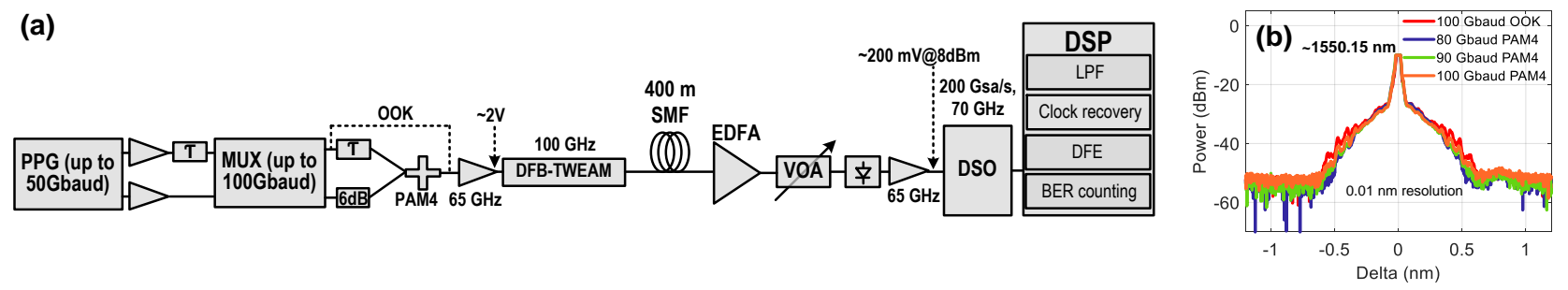

Figure 1. (a) Experimental setup (PPG: pulse-pattern generator), (b) optical spectra of the 100 Gbaud OOK and PAM4 signals (Mux: multiplexer, T: delay line, DFB-TWEAM: distributed feedback laser with traveling-wave electroabsorption modulator, SMF: single-mode fiber, EDFA: erbium-doped fiber amplifier, VOA: variable optical attenuator, DSO: digital storage oscilloscope, DSP: digital signal processing, LPF: low-pass filter, DFE: decision feedback equalizer, BER: bit error rate).

In this paper, we wish to quantify this simple PAM4 generation scheme's impact on the introduced penalty. Therefore, we gradually increase baud rate from 80 Gbaud to 100 Gbaud. Then, the PAM4 signal is amplified in a $65 \mathrm{GHz}$ linear amplifier to drive the EML. We achieve around 2 volts of the electrical signal (peak to peak) for OOK and PAM4 high-speed signals. EML is based on a monolithically integrated distributed feedback laser with traveling-wave electroabsorption modulator (DFB-TWEAM) designed by KTH, fabricated by KTH and Syntune, and packaged by $\mathrm{u}^{2} \mathrm{t}$ Photonics. The DFB laser threshold current is around $25 \mathrm{~mA}$ and the slope efficiency is $0.04 \mathrm{~W} / \mathrm{A}$. The wavelength of the DFBTWEAM is $1550.15 \mathrm{~nm}$ in this experiment. The EML has a $3 \mathrm{~dB}$ bandwidth beyond $100 \mathrm{GHz}$ with less than $2 \mathrm{~dB}$ ripple in the passband, which indicates high phase linearity [39]. These figures of merits make this EML considered an excellent candidate for four optical lanesbased $800 \mathrm{GbE}$ solution $[19,20,36]$. We use a current of $120 \mathrm{~mA}$ for the DFB and a voltage of $-1.85 \mathrm{~V}$ for the TWEAM, resulting in around a $5 \mathrm{~dB}$ extinction ratio. We achieve an output power of $-0.9 \mathrm{dBm}$. Higher power values can be achieved with a reduced bias voltage, which also reduces the extinction ratio of a modulated signal. In the experiment, we found a trade-off between the bias voltage and the extinction ratio. In Figure 1b, one can see that the modulated optical spectra are around $1550.15 \mathrm{~nm}$ for the OOK and PAM4. The optical link consists of $400 \mathrm{~m}$ of SMF. The receiver consists of a preamplifier, a variable optical attenuator (VOA), a $>100 \mathrm{GHz} \mathrm{PD}$ from $\mathrm{u}^{2} \mathrm{t}$ with a responsivity of $0.5 \mathrm{~A} / \mathrm{W}$, a $65 \mathrm{GHz}$ linear amplifier, and a $200 \mathrm{GSa} / \mathrm{s}$, a $70 \mathrm{GHz}$ bandwidth Tektronix DSO (DPO77002SX). An automatic gain-controlled erbium-doped fiber amplifier (EDFA) with fixed output power is employed as the preamplifier due to a low PD responsivity. The noise figure of the amplifier is around $4.5 \mathrm{~dB}$. Due to limited maximum input power to the photodetector, an additional $65 \mathrm{GHz}$ linear amplifier is used to ensure around $200 \mathrm{mV}$ peak to peak voltage of the received signals required for better performance. In the case of OOK, we could skip the optical amplification when no variable optical attenuator is used. Instead, we keep the amplifier for OOK to compare it to PAM4 under similar noise conditions. The sampled signal is then processed offline using a typical DSP. We perform low-pass filtering, clock recovery, and resampling to ensure 1 sample per symbol for a symbol-spaced DFE with a different configuration of feed-forward taps (FFT) and feedback taps (FBT) to overcome inter symbol interference (ISI) in the presence of the noise. The main limitations are due to the limited effective $3 \mathrm{~dB}$ bandwidth of the electrical components and the implementation penalty itself. After the equalization, we perform BER counting. We consider hard-decision forward error correction code (HD-FEC) with $7 \%$ and $20 \%$ overheads $(\mathrm{OH})$ and softdecision FEC (SD-FEC) with 20\% OH with pre-FEC BERs at 5E-3 [49], 1.1E-2 [50], and 2E-2, respectively. We use the SD-FEC due to the poor electrical $b 2 b$ signal quality related to the implementation penalty. We study different DFE configurations to improve the received signal quality (see Figure 2). We express the performance in terms of ROP required for a certain BER. We use a 7\% HD-FEC limit of 5E-3 and a 20\% SD-FEC limit of 2E-2 for OOK 
and PAM4 signals, respectively. For both signals, we fix the number of feedback taps to 15 and a low-pass filter (LPF) bandwidth to $0.75^{*}$ baud rate. Then we choose the feed-forward taps number to be 3, 7, 11, and 15 for OOK and 15, 29, 43, 57, and 71 for PAM4 signals.

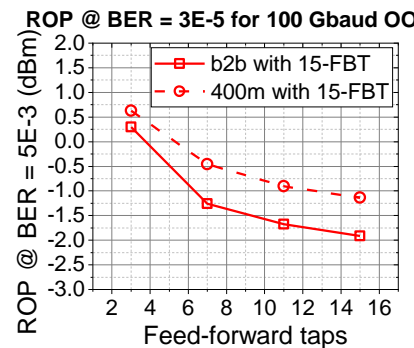

(a)

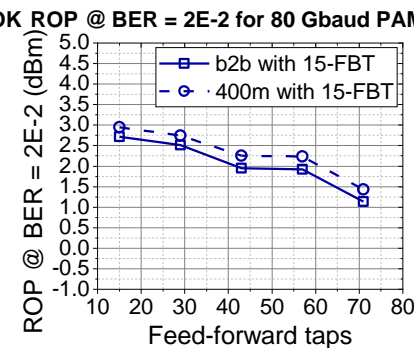

(b)

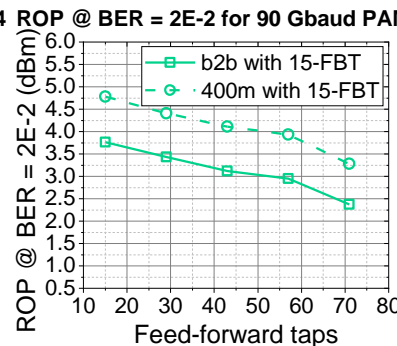

(c)

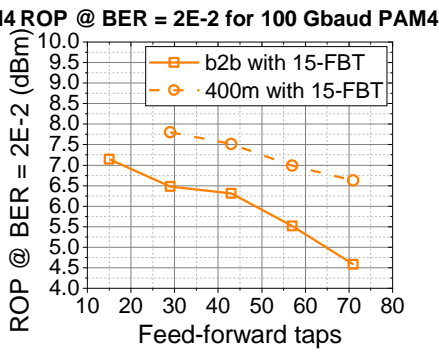

(d)

Figure 2. Received optical power versus different configurations of decision feedback equalizers for (a) $100 \mathrm{Gbaud}$ OOK, (b) 80 Gbaud PAM4, (c) 90 Gbaud PAM4, and (d) 100 Gbaud PAM4 signals.

From Figure 2, we observe that with the increase in the feed-forward tap number we require lower received optical power to achieve the specified pre-FEC BER. For $100 \mathrm{Gbaud}$ OOK signal with 15-tap FFT and 15-tap FBT equalizer, we see around $0.7 \mathrm{~dB}$ power penalty for $400 \mathrm{~m}$ SMF transmission compared to optical back-to-back. If we compare PAM4 signals with the same equalizer, we get a power penalty of around $0.2 \mathrm{~dB}$ for 80 Gbaud and $1 \mathrm{~dB}$ for 90 Gbaud signals. For 100 Gbaud PAM4 signal after $400 \mathrm{~m}$ transmission over the SMF, we could not achieve a bit error rate of $2 \mathrm{E}-2$ for any received power. This forced us to increase the complexity of the equalizer. Still, we observe a higher power penalty-around $1.3 \mathrm{~dB}$ with 29-tap FFT and 15-tap FBT equalizer. For further analysis, we choose equalizers with higher complexity to reduce the required ROP for a certain BER.

Afterward, we obtain the bit error rate as a function of $\mathrm{LPF}_{\mathrm{BW}} /$ baud rate for OOK and PAM4 signals (see Figure 3). During the processing, we set the $\mathrm{LPF}_{\mathrm{BW}} /$ baud rate from 0.45 to 0.8 . We choose received optical power of $-1 \mathrm{dBm}$ for OOK and $8 \mathrm{dBm}$ for PAM4 signals to observe the BER performance around the specific FEC limits mentioned above. For the OOK signal, both curves are mostly below the 7\% HD-FEC limit. Similar performance for optical b2b and after $400 \mathrm{~m}$ is obtained with a 15-tap FFT and 15-tap FBT equalizer. We see that the best signal performance is for the $\mathrm{LPF}_{\mathrm{BW}} /$ baud rate of 0.575 , which is now chosen for further processing. For PAM4 signals, we must increase the equalizer's complexity. We increase the number of feed-forward taps to 71 and keep the same number of feedback taps, i.e., FBT $=15$. For 80 Gbaud PAM4 signal, we managed to reach BERs below 5E-3 for above 0.6 of $\mathrm{LPF}_{\mathrm{BW}} /$ baud rate for both curves. It is also the case for the optical b2b curve of 90 Gbaud PAM4 signals with a 71-tap FFT and 15-tap FBT equalizer and $\mathrm{LPF}_{\mathrm{BW}} /$ baud rate of 0.75 . We need to increase the HD-FEC overhead to $20 \%$ to detect 90 Gbaud PAM4 signals after $400 \mathrm{~m}$ of SMF transmission. In the case of 100 Gbaud PAM4, the performance is below the $20 \%$ SD-FEC limit. For all three cases of the PAM4 signals, we choose $\mathrm{LPF}_{\mathrm{BW}} / \mathrm{baud}$ rate of 0.75 for further analysis.

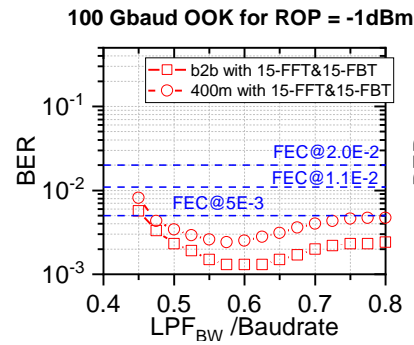

(a)

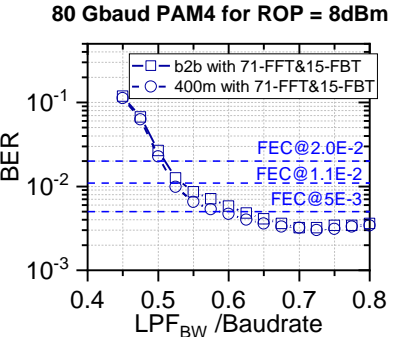

(b)

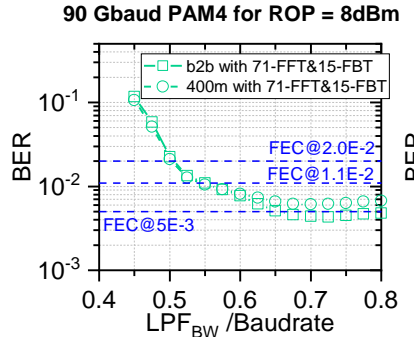

(c)

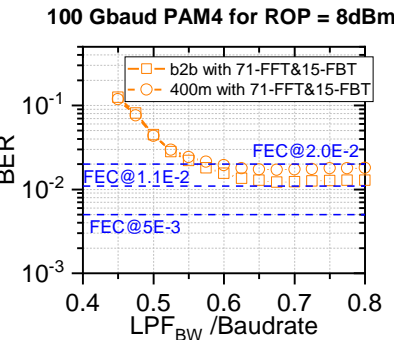

(d)

Figure 3. Bit error rate versus $\mathrm{LPF}_{\mathrm{bw}}$ /baud rate for (a) $100 \mathrm{Gbaud}$ OOK, (b) 80 Gbaud PAM4, (c) 90 Gbaud PAM4, and (d) 100 Gbaud PAM4 signals. We use minus $1 \mathrm{dBm}$ received optical power for OOK and $8 \mathrm{dBm}$ for PAM4 signals. 
Finally, we show bit error rate, eye-diagrams, and amplitude histograms for OOK and PAM4 signals after the optical b2b and $400 \mathrm{~m}$ transmission. BER results as a function of received power for different signals and DFE configurations are shown in Figure 4a. The BER curves are obtained using a 15-FFT and 15-FBT equalizer for OOK and a 71-FFT and 15-FBT for PAM4. In the case of OOK, we manage to achieve the 7\% HD-FEC limit for both the optical b2b and the 400-m transmission. We observe around $0.5 \mathrm{~dB}$ received power penalty at the $7 \%$ HD-FEC limit due to a large implementation penalty which adds up to the transmission penalty over $400 \mathrm{~m}$ of SMF. The implementation penalty can also be observed from the equalized eye diagram and histograms in Figure $4 \mathrm{~b}$. Further, we study transmission with 80 Gbaud PAM4 signals. One can observe a severe PAM4 signal degradation due to both higher sensitivity requirements and poor electrical signal performance at the transmitter due to the implementation penalty. This can be seen from the eye diagrams and amplitude histograms in Figure 4. The suboptimal passive combining ratio due to the imperfect components explains such worse performance. The electrical signal performance imposes a strict error floor for PAM4 signals. One can observe that the use of a 71-FFT and 15-FBT equalizer allows achieving below the 7\% HD-FEC performance limit after $400 \mathrm{~m}$ of SMF for 80 Gbaud PAM4 signals with a small penalty compared to the optical $b 2 b$. We need to increase the number of equalizer feed-forward taps significantly compared to the OOK case to reduce the impact of the implementation penalty on highspeed PAM4 signals. When increasing the PAM4 signal data rate to $90 \mathrm{Gbaud}$, we obtain the performance below the HD-FEC limit only for optical $b 2 b$. The performance has degraded after $400 \mathrm{~m}$ transmission and we need to increase the overhead to $20 \%$ for the HD-FEC. In this case, we observe around $1.3 \mathrm{~dB}$ received power penalty. Then, we increase the transmission speed to 100 Gbaud and achieve only the $20 \%$ SD-FEC limit. Here, we observe around $2.3 \mathrm{~dB}$ of received power penalty. We achieve $149 \mathrm{Gbit} / \mathrm{s}, 150 \mathrm{Gbit} / \mathrm{s}$, and $166 \mathrm{Gbit} / \mathrm{s}$ post-FEC bitrates for $80 \mathrm{Gbaud}, 90 \mathrm{Gbaud}$, and 100 Gbaud PAM4 signals and $93 \mathrm{Gbit} / \mathrm{s}$ for 100 Gbaud OOK signal.
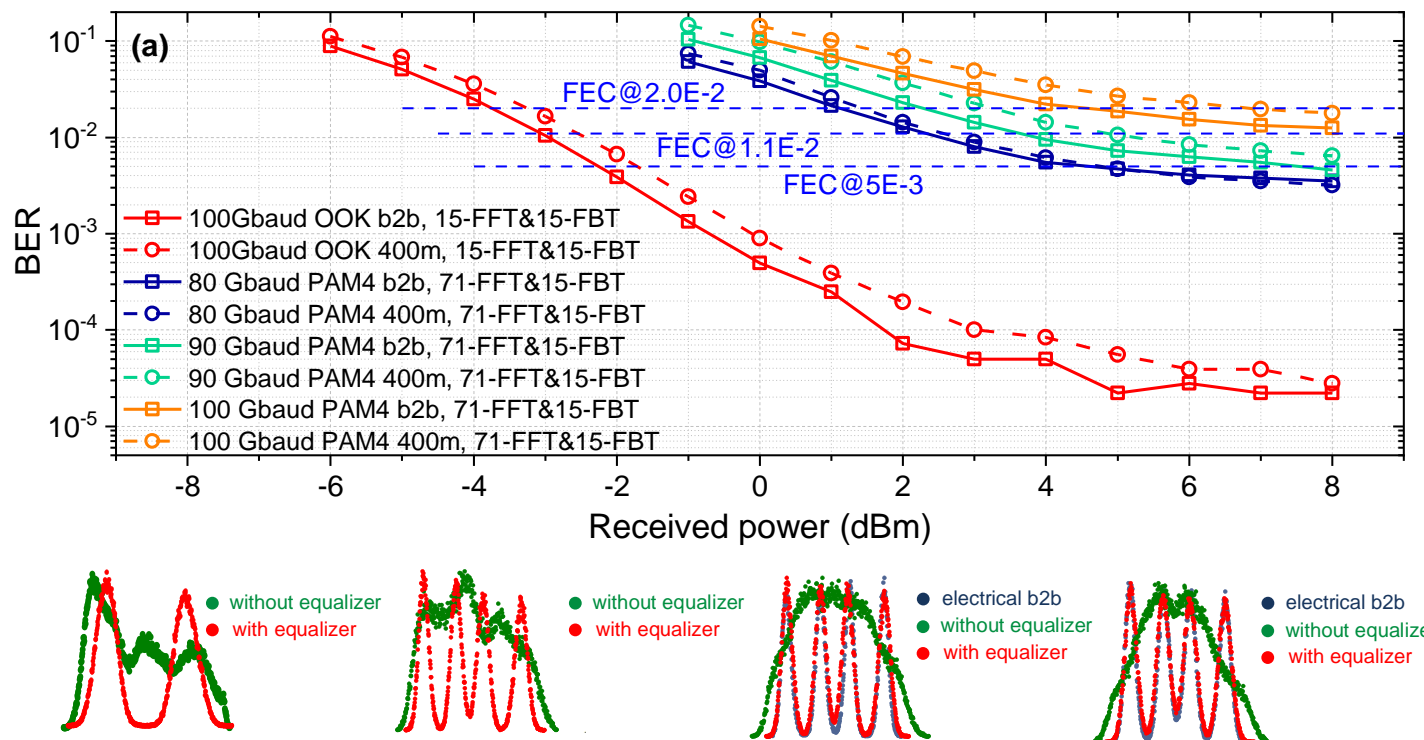

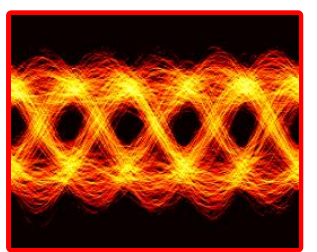

(b)100 Gbaud OOK

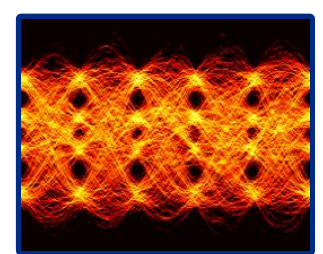

(c) 80 Gbaud PAM4

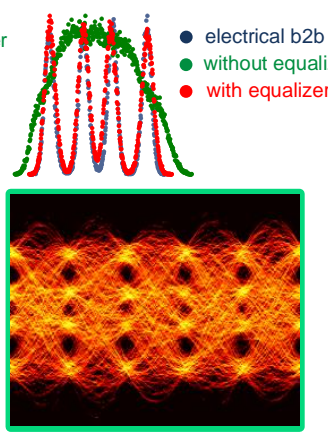

(d) 90 Gbaud PAM4

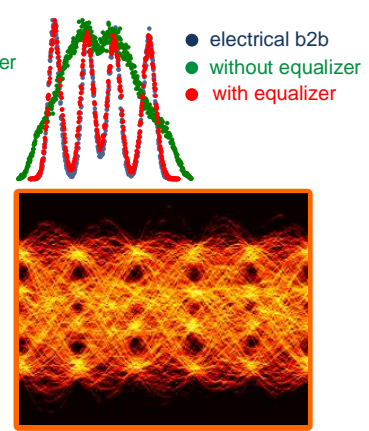

(e) 100 Gbaud PAM4

Figure 4. (a) BER curves for OOK and PAM4 signal for b2b and $400 \mathrm{~m}$, (b-e) eye diagram and histograms for optical b2b at ROP of $8 \mathrm{dBm}$. 
We point out that the histograms obtained with the 71-FFT and 15-FBT DFE for the electrical b2b and the optical b2b signals at 90 Gbaud and 100 Gbaud are comparable in their performance (see Figure $4 d, e$ ). We measure the electrical b2b signals before the DFB-TWEAM and after the $65 \mathrm{GHz}$ amplifier. We attribute the main implementation penalty to electrical components in the transmitter which could be remedied by improving the bandwidth and linearity in the electrical domain. Further improvement in the electrical signal generation scheme for PAM potentially would allow achieving better signal quality and, thus, improving the link latency thanks to a reduced FEC [21,31]. This would result in an even higher baud rate for multilevel signal transmission with the EML [19]. The operational wavelength of the EML is around $1550 \mathrm{~nm}$ in the measurements. The obtained results demonstrate the capability of the EML to enable $800 \mathrm{GbE}$ client-side links for short-reach optical interconnect applications.

\section{Simulation Setup and Results}

We perform numerical simulations to complement the experiments. We use the MATLAB-based Robochameleon framework [51]. It is a coding framework and component library for simulation and experimental analysis of optical communication systems. We focus on transmitter imperfections and CD tolerance. The simulation setup is shown in Figure 5 and its main configuration parameters are specified in Table 1 . The transmitter includes a digital to analog converter (DAC), an intensity modulator (IM), and a continuous wave $(\mathrm{CW})$ laser. The link is based on lossless single-mode fiber. In the receiver, we have a variable optical attenuator, a photodetector with a transimpedance amplifier (PD-TIA), and an ADC. Then we perform a typical DSP to recover transmitted bits. We choose a simple DFE with 6-FFT and 3-FBT to perform channel equalization since the modulator is driven in the linear region and we have a linear dispersive fiber link. We use hard-decision demodulators for the 100 Gbaud OOK, PAM4, and PAM8 signals after the equalization. We set a CD coefficient to $16 \mathrm{ps} / \mathrm{nm} / \mathrm{km}$. The PD has a bandwidth of $112 \mathrm{GHz}$ and the Gaussian receiver filter has bandwidth of $75 \mathrm{GHz}$, as can be seen from Table 1. We use root-raised cosine pulse shaping with 0.75 roll-off to have similar signals as in the experiment.

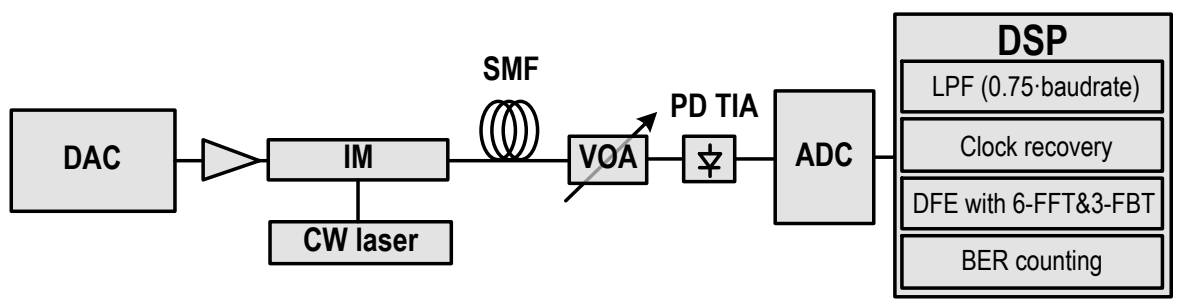

Figure 5. Simulation setup. DAC: digital to analog converter, $\mathrm{CW}$ laser: continuous-wave laser, IM: intensity modulator, SMF: single-mode fiber, VOA: variable optical attenuator, PD-TIA: photodetector with a transimpedance amplifier, ADC: analog to digital converter, DSP: digital signal processing, LPF: low-pass filter, DFE: decision feedback equalizer, FFT: feed-forward taps, FBT: feedback taps, BER: bit error rate.

We study the required ROP for a certain BER (see Figure $6 a-c$ ) and the power penalty (see Figure 6d-f) for the different ENOB and ER at the transmitter for 100 Gbaud OOK, PAM4, and PAM8 signals for optical b2b. The power penalty was calculated by using separate references for each modulation format. For the OOK and PAM4 signals, we sweep the ENOB from 2 to 6, while for the PAM8 from 3 to 7 . This is because PAM8 has more amplitude levels to be represented. For all three modulation formats, we choose the extinction ratio to be from 3 to $10 \mathrm{~dB}$. Values are color-coded with the respect to the minimum and the maximum ROP and penalty values, respectively. One can observe from the curves that the extinction ratio of the signal at the transmitter has a crucial impact on the required ROP for a certain BER and the power penalty. In all numerical simulations, we are using the $7 \% \mathrm{HD}-\mathrm{FEC}$ limit with a BER of 5E-3. One can see that the required ROP 
is modulation format-dependent. For instance, the required ROP is around minus $4.5 \mathrm{dBm}$ for OOK, minus $1 \mathrm{dBm}$ for PAM4, and $2 \mathrm{dBm}$ for PAM8 when the ER is set to $5 \mathrm{~dB}$ and the ENOB to 5 . We observe around $4 \mathrm{~dB}$ power penalty for OOK and PAM4 signals for the same ER and ENOB. The penalty is slightly higher for PAM8. For further simulations, we set $\mathrm{ER}=5 \mathrm{~dB}$ and $\mathrm{ENOB}=5$, because it is the closest value to the experiment.

Table 1. Simulation setup parameters.

\begin{tabular}{cc}
\hline Transmitter & Parameters \\
\hline Modulation format & OOK, PAM4, PAM8 \\
Pulse shaping & Root raised cosine \\
Roll-off & 0.75 \\
ENOB & 2 to 7 or 5 \\
Modulator driving signal Vpp & $0.4^{*} \mathrm{~V} \pi$ \\
Laser RIN & $145 \mathrm{~dB} / \mathrm{Hz}$ \\
Extinction ratio & 3 to 10 or 5 \\
Output power & $5 \mathrm{dBm}$ \\
Wavelength & $1550 \mathrm{~nm}$ \\
\hline Lossless Channel & Parameters \\
\hline Dispersion & $16 \mathrm{ps} / \mathrm{nm}$ \\
Length & 0 to $1000 \mathrm{~m}$ \\
\hline Receiver & Parameters \\
\hline Photodetector & PIN-TIA \\
Photodetector responsivity & $0.5 \mathrm{~A} / \mathrm{W}$ \\
Noise current & $18 \mathrm{pA} / \sqrt{ } \mathrm{Hz}$ \\
Photodetector filter model & $112 \mathrm{GHz}$ \\
PD-TIA cut-off bandwidth & Parameters \\
\hline Digital Signal Processing & $0.75^{*}$ baud rate \\
Gaussian filter bandwidth & OOK $/ \mathrm{PAM}$ \\
Equalizer & $5 \mathrm{E}-3$ \\
\hline Demodulation & Decision feedback equalizer \\
FEC limit &
\end{tabular}

$\overline{\mathrm{V} p}$ : peak-to-peak voltage; $\mathrm{V}_{\pi}=2 \mathrm{~V}$.

Fiber's CD will limit the transmission distance if we consider single-mode operations in the C-band. Therefore, we also investigate $\mathrm{CD}$ tolerance for different modulation formats. We are not considering chirp at the transmitter to show degradation coming only from fiber's dispersion at the operational wavelength of $1550 \mathrm{~nm}$. The received power penalty as a function of transmission distance is shown in Figure 7. We obtain curves for a 6-FFT and 3FBT equalizer. Considering a $1 \mathrm{~dB}$ power penalty, the 100 Gbaud PAM4 can be transmitted up to $1000 \mathrm{~m}$. It is more than two times $(2 \times)$ increased compared to the experimental demonstration. For the 100 Gbaud OOK, the fiber distance can be increased beyond $1000 \mathrm{~m}$ while maintaining the same penalty and equalizer parameters. The transmission distances over SMF can be significantly improved by the microwave design of the EML that can be applied to a semiconductor material with a larger bandgap to achieve modulation at zero dispersion wavelength [39]. 


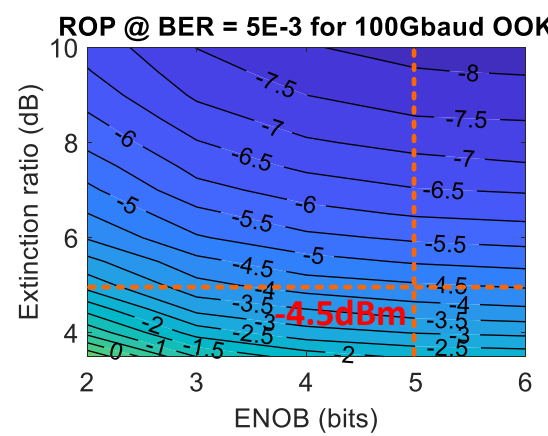

(a)

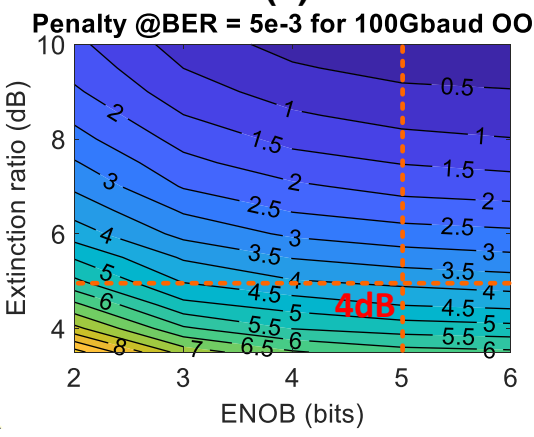

(d)

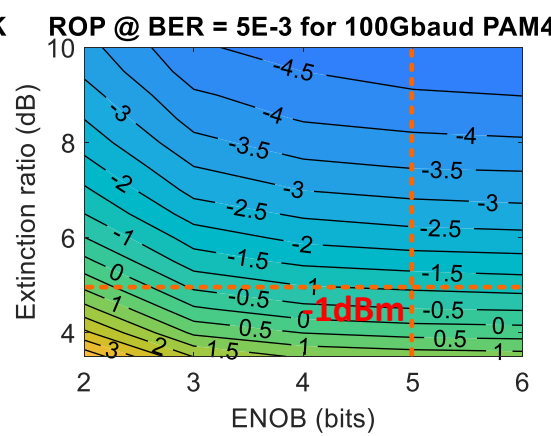

(b)

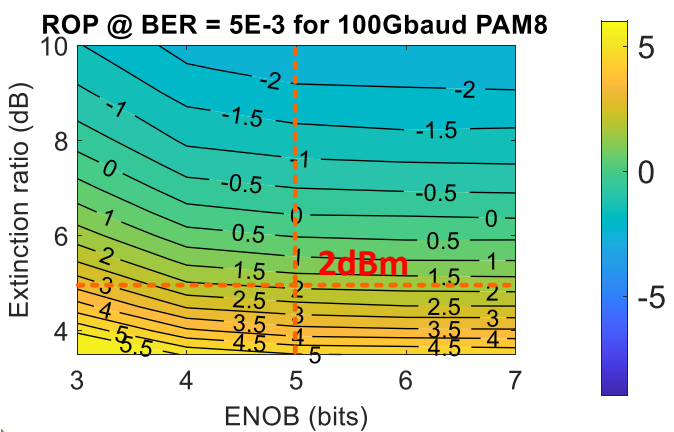

(c)

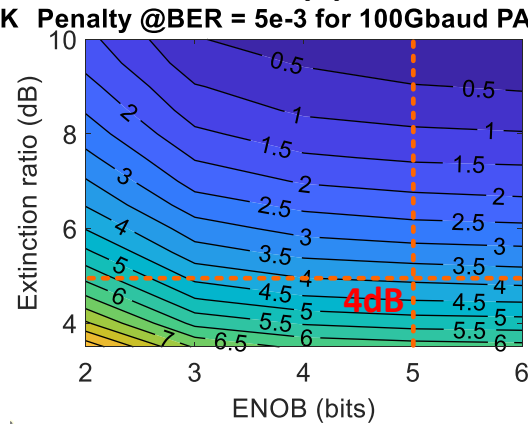

(e)

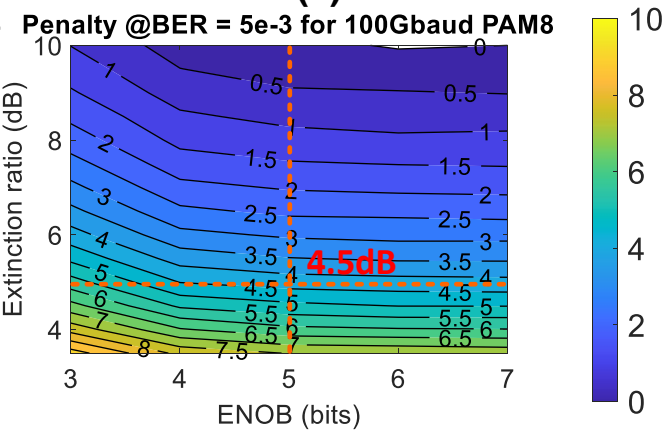

(f)

Figure 6. Extinction ratio versus the effective number of bits in terms of received optical power and penalty for $100 \mathrm{Gbaud}$ $(\mathbf{a}, \mathbf{d})$ OOK, (b,e) 8PAM4, and (c,f) PAM8 signals for 6-FFT and 3FBT equalizer configuration at optical b2b.

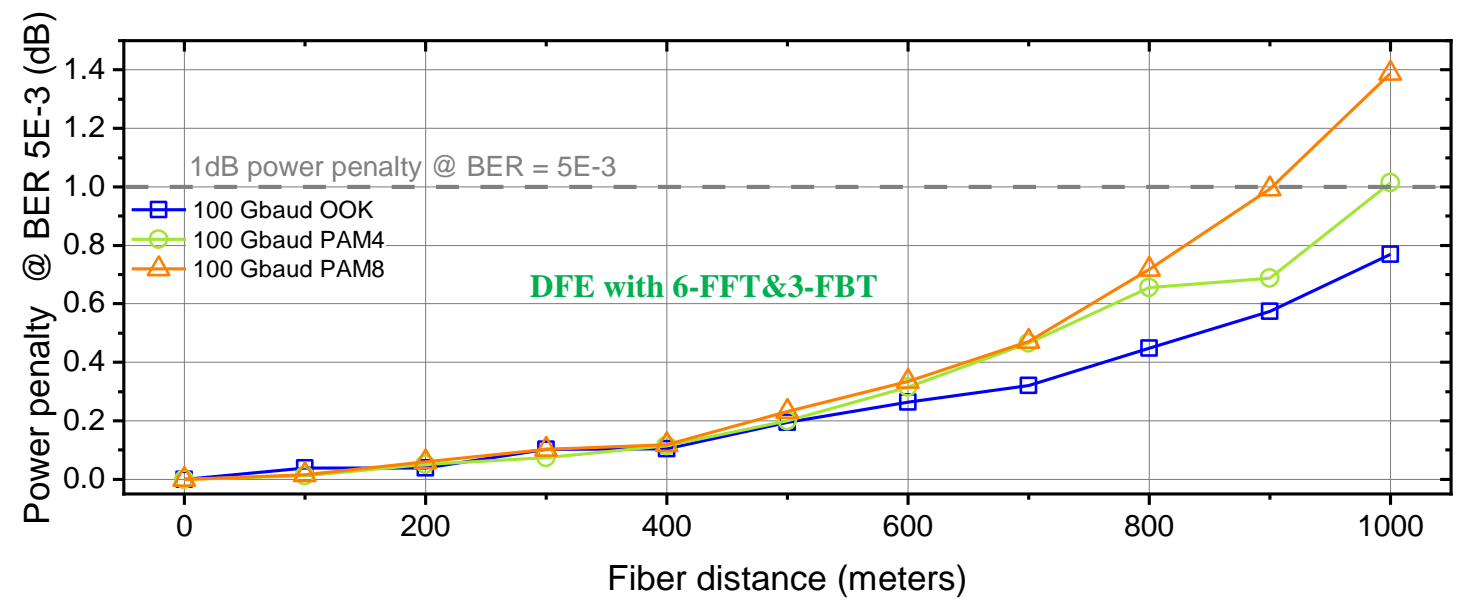

Figure 7. Received power penalty (at BER $=5 \mathrm{E}-3$ ) as a function of transmitted distance for 100 Gbaud OOK, PAM4, and PAM8 signals with 6-FFT and 3FBT equalizer configuration (see inset).

\section{Conclusions}

We have demonstrated 100 Gbaud OOK and PAM4 transmitter performance in Cband for short-reach optical interconnect applications as a potential solution for four/eight optical lanes $800 \mathrm{GbE}$ links. We achieve $149 \mathrm{Gbit} / \mathrm{s}, 150 \mathrm{Gbit} / \mathrm{s}$, and $166 \mathrm{Gbit} / \mathrm{s}$ postFEC bitrates for 80 Gbaud, 90 Gbaud, and 100 Gbaud PAM4 signals and 93 Gbit/s for 100 Gbaud OOK signal. Furthermore, we perform numerical simulations to study the impact of transmitter parameters and chromatic dispersion impact of power penalty for 100 Gbaud OOK, PAM4, and PAM8 signals. We observe the significant chromatic dispersion impact in both experiments and simulations. 
Author Contributions: Conceptualization, O.O., X.P., A.U.; methodology, O.O., X.P., A.U., R.S., V.B., S.P.; software, O.O., X.P.; validation, O.O., X.P., A.U., S.S.; formal analysis, O.O., X.P., A.U., R.S., S.S.; investigation, O.O., X.P., A.U., R.S.; resources, O.O.; data curation, O.O., X.P., A.U., R.S., S.S.; writing-original draft preparation, O.O.; writing—review and editing, X.P., A.U., R.S., S.S., V.B., G.J., S.P.; visualization, O.O., X.P., A.U.; supervision, V.B., G.J., S.P.; project administration, O.O., R.S.; funding acquisition, O.O., R.S., V.B., S.P. All authors have read and agreed to the published version of the manuscript.

Funding: This work was supported by the ERDF-funded CARAT project No. 1.1.1.2/VIAA/4/20/660 and the EU RIA TWILIGHT project no. 871741.

Institutional Review Board Statement: Not applicable.

Informed Consent Statement: Not applicable.

Data Availability Statement: Not applicable.

Acknowledgments: We acknowledge Tektronix for lending us the $200 \mathrm{GSa} / \mathrm{s} 70 \mathrm{GHz}$ oscilloscope (DPO77002SX).

Conflicts of Interest: The authors declare no conflict of interest.

\section{References}

1. Mestre, M.A.; Mardoyan, H.; Caillaud, C.; Rios-Müller, R.; Renaudier, J.; Jennevé, P.; Blache, F.; Pommereau, F.; Decobert, J.; Jorge, F.; et al. Compact InP-based DFB-EAM enabling PAM-4 112 Gb/s transmission over 2 km. J. Lightwave Technol. 2016, 34, 1572-1578. [CrossRef]

2. Mardoyan, H.; Mestre, M.A.; Rios-Müller, R.; Konczykowska, A.; Renaudier, J.; Jorge, F.; Duval, B.; Dupuy, J.; Ghazisaeidi, A.; Jennevé, P.; et al. Single carrier 168-Gb/s line-rate PAM direct detection transmission using high-speed selector power DAC for optical interconnects. J. Lightwave Technol. 2016, 34, 1593-1598. [CrossRef]

3. Xiang, M.; Xing, Z.; El-Fiky, E.; Morsy-Osman, M.; Zhuge, Q.; Plant, D.V. Single-lane 145 Gbit/s IM/DD transmission with faster-than-nyquist PAM4 signaling. IEEE Photonics Technol. Lett. 2018, 30, 1238-1241. [CrossRef]

4. Cheng, Q.; Bahadori, M.; Glick, M.; Rumley, S.; Bergman, K. Recent advances in optical technologies for data centers: A review. Optica 2018, 5, 1354-1370. [CrossRef]

5. Cisco Inc. Cisco Annual Internet Report (2018-2023); Cisco: San Jose, CA, USA, 2020.

6. Sun, H.; Torbatian, M.; Karimi, M.; Maher, R.; Thomson, S.; Tehrani, M.; Gao, Y.; Kumpera, A.; Soliman, G.; Kakkar, A.; et al. 800G DSP ASIC design using probabilistic shaping and digital sub-carrier multiplexing. J. Lightwave Technol. 2020, 38, 4744-4756. [CrossRef]

7. Karinou, F.; Prodaniuc, C.; Stojanovic, N.; Ortsiefer, M.; Daly, A.; Hohenleitner, R.; Kögel, B.; Neumeyr, C. Directly PAM-4 modulated 1530-nm VCSEL enabling 56 Gb/s/ $\lambda$ data-center interconnects. IEEE Photonics Technol. Lett. 2015, 27, 1872-1875. [CrossRef]

8. Filer, M.; Searcy, S.; Fu, Y.; Nagarajan, R.; Tibuleac, S. Demonstration and performance analysis of 4 Tb/s DWDM metro-DCI system with 100G PAM4 QSFP28 modules. In Optical Fiber Communication Conference, Proceedings of the Optical Fiber Communication Conference, Los Angeles, CA, USA, 19-23 March 2017; Optical Society of America: Los Angeles, CA, USA, $2017 ;$ p. W4D.4.

9. Nagarajan, R.; Filer, M.; Fu, Y.; Kato, M.; Rope, T.; Stewart, J. Silicon photonics-based 100 Gbit/s, PAM4, DWDM data center interconnects. IEEE/OSA J. Opt. Commun. Netw. 2018, 10, 25-36. [CrossRef]

10. Matsui, Y.; Schatz, R.; Pham, T.; Ling, W.A.; Carey, G.; Daghighian, H.M.; Adams, D.; Sudo, T.; Roxlo, C. 55 GHz bandwidth distributed reflector laser. J. Lightwave Technol. 2017, 35, 397-403. [CrossRef]

11. Pang, X.; Ozolins, O.; Gaiarin, S.; Kakkar, A.; Navarro, J.R.; Olmedo, M.I.; Schatz, R.; Udalcovs, A.; Westergren, U.; Zibar, D.; et al. Experimental study of 1.55- $\mu \mathrm{m}$ EML-based optical IM/DD PAM-4/8 short reach systems. IEEE Photonics Technol. Lett. 2017, 29, 523-526. [CrossRef]

12. Zhong, K.; Zhou, X.; Wang, Y.; Wang, Y.; Zhou, W.; Chen, W.; Zeng, L.; Wang, L.; Lau, A.P.T.; Lu, C. Transmission of a 120-GBd PM-NRZ signal using a monolithic double-side EML. IEEE Photonics Technol. Lett. 2016, 28, 2176-2179. [CrossRef]

13. Samani, A.; Chagnon, M.; El-Fiky, E.; Patel, D.; Jacques, M.; Veerasubramanian, V.; Plant, D.V. Silicon photonics modulator architectures for multi-level signal generation and transmission. In Proceedings of the 2017 Optical Fiber Communications Conference and Exhibition (OFC), Los Angeles, CA, USA, 19-23 March 2017; pp. 1-3.

14. Verplaetse, M.; Lin, R.; Kerrebrouck, J.V.; Ozolins, O.; Keulenaer, T.D.; Pang, X.; Pierco, R.; Vaernewyck, R.; Vyncke, A.; Schatz, R.; et al. Real-time $100 \mathrm{~Gb} / \mathrm{s}$ transmission using three-level electrical duobinary modulation for short-reach optical interconnects. $J$. Lightwave Technol. 2017, 35, 1313-1319. [CrossRef]

15. Zhong, K.; Mo, J.; Grzybowski, R.; Lau, A.P.T. 400 Gbps PAM-4 signal transmission using a monolithic laser integrated silicon photonics transmitter. In Proceedings of the 2019 Optical Fiber Communications Conference and Exhibition (OFC), San Diego, CA, USA, 3-7 March 2019; pp. 1-3. 
16. Kanazawa, S.; Yamazaki, H.; Nakanishi, Y.; Ueda, Y.; Kobayashi, W.; Muramoto, Y.; Ishii, H.; Sanjoh, H. 214-Gb/s 4-PAM operation of flip-chip interconnection EADFB laser module. J. Lightwave Technol. 2017, 35, 418-422. [CrossRef]

17. Lange, S.; Wolf, S.; Lutz, J.; Altenhain, L.; Schmid, R.; Kaiser, R.; Schell, M.; Koos, C.; Randel, S. 100 GBd intensity modulation and direct detection with an InP-based monolithic DFB laser Mach-Zehnder modulator. J. Lightwave Technol. 2018, 36, 97-102. [CrossRef]

18. Ozolins, O.; Pang, X.; Udalcovs, A.; Schatz, R.; Westergren, U.; Navarro, J.R.; Kakkar, A.; Nordwall, F.; Engenhardt, K.M.; Chen, J.; et al. 100 Gbaud 4PAM link for high speed optical interconnects. In Proceedings of the 2017 European Conference on Optical Communication (ECOC), Gothenburg, Sweden, 17-21 September 2017; pp. 1-3.

19. Estarán, J.M.; Mardoyan, H.; Jorge, F.; Ozolins, O.; Udalcovs, A.; Konczykowska, A.; Riet, M.; Duval, B.; Nodjiadjim, V.; Dupuy, J.; et al. 140/180/204-Gbaud OOK transceiver for inter- and intra-data center connectivity. J. Lightwave Technol. 2019, 37, 178-187. [CrossRef]

20. Pang, X.; Ozolins, O.; Lin, R.; Zhang, L.; Udalcovs, A.; Xue, L.; Schatz, R.; Westergren, U.; Xiao, S.; Hu, W.; et al. 200 Gbps/Lane IM/DD technologies for short reach optical interconnects. J. Lightwave Technol. 2020, 38, 492-503. [CrossRef]

21. Ozolins, O.; Zhang, L.; Udalcovs, A.; Louchet, H.; Dippon, T.; Gruen, M.; Pang, X.; Schatz, R.; Westergren, U.; Xiao, S.; et al. 100 Gbaud PAM4 link without EDFA and post-equalization for optical interconnects. In Proceedings of the 45th European Conference on Optical Communication (ECOC 2019), Dublin, Ireland, 22-26 September 2019; pp. 1-4.

22. Mardoyan, H.; Mestre, M.A.; Estarán, J.M.; Jorge, F.; Blache, F.; Angelini, P.; Konczykowska, A.; Riet, M.; Nodjiadjim, V.; Dupuy, J.; et al. 84-, 100-, and 107-GBd PAM-4 intensity-modulation direct-detection transceiver for datacenter interconnects. J. Lightwave Technol. 2017, 35, 1253-1259. [CrossRef]

23. Yang, C.; Li, W.; Yu, S. Single channel 224 Gbit/s (56-GBaud) PAM-16 transmission using linear digital pre-distortion. Electron. Lett. 2017, 53, 1420-1422. [CrossRef]

24. Chagnon, M.; Lessard, S.; Plant, D.V. 336 Gb/s in direct detection below KP4 FEC threshold for intra data center applications. IEEE Photonics Technol. Lett. 2016, 28, 2233-2236. [CrossRef]

25. Wei, J.; Rahman, T.; Calabrò, S.; Stojanovic, N.; Zhang, L.; Xie, C.; Ye, Z.; Kuschnerov, M. Experimental demonstration of advanced modulation formats for data center networks on $200 \mathrm{~Gb} / \mathrm{s}$ lane rate IMDD links. Opt. Express 2020, 28, 35240-35250. [CrossRef] [PubMed]

26. Estarán, J.M.; Almonacil, S.; Rios-Müller, R.; Mardoyan, H.; Jenneve, P.; Benyahya, K.; Simonneau, C.; Bigo, S.; Renaudier, J.; Charlet, G. Sub-baudrate sampling at DAC and ADC: Toward 200G per lane IM/DD systems. J. Lightwave Technol. 2019, 37, 1536-1542. [CrossRef]

27. Che, D.; Matsui, Y.; Schatz, R.; Rodes, R.; Khan, F.; Kwakernaak, M.; Sudo, T. 200-Gb/s direct modulation of a 50-GHz class laser with advanced digital modulations. J. Lightwave Technol. 2021, 39, 845-852. [CrossRef]

28. Ozolins, O.; Estaran, J.M.; Udalcovs, A.; Jorge, F.; Mardoyan, H.; Konczykowska, A.; Riet, M.; Duval, B.; Nodjiadjim, V.; Dupuy, J.; et al. 140 Gbaud on-off keying links in C-band for short-reach optical interconnects. In Proceedings of the 2018 European Conference on Optical Communication (ECOC), Rome, Italy, 23-27 September 2018; pp. 1-3.

29. Zhang, Q.; Stojanovic, N.; Prodaniuc, C.; Xie, C.; Koenigsmann, M.; Laskowski, P. Single-lane 180 Gbit/s PAM-4 signal transmission over $2 \mathrm{~km}$ SSMF for short-reach applications. Opt. Lett. 2016, 41, 4449-4452. [CrossRef] [PubMed]

30. Zhong, K.; Zhou, X.; Huo, J.; Yu, C.; Lu, C.; Lau, A.P.T. Digital signal processing for short-reach optical communications: A review of current technologies and future trends. J. Lightwave Technol. 2018, 36, 377-400. [CrossRef]

31. Ozolins, O.; Pang, X.; Udalcovs, A.; Lin, R.; Kerrebrouck, J.V.; Gan, L.; Zhang, L.; Tang, M.; Fu, S.; Schatz, R.; et al. $7 \times 149$ Gbit/s PAM4 transmission over $1 \mathrm{~km}$ multicore fiber for short-reach optical interconnects. In Proceedings of the $2018 \mathrm{Conference} \mathrm{on}$ Lasers and Electro-Optics (CLEO), San Jose, CA, USA, 13-18 May 2018; pp. 1-2.

32. Chagnon, M. Optical communications for short reach. J. Lightwave Technol. 2019, 37, 1779-1797. [CrossRef]

33. Olmedo, M.I.; Zuo, T.; Jensen, J.B.; Zhong, Q.; Xu, X.; Popov, S.; Monroy, I.T. Multiband carrierless amplitude phase modulation for high capacity optical data links. J. Lightwave Technol. 2014, 32, 798-804. [CrossRef]

34. Zhang, L.; Hong, X.; Pang, X.; Ozolins, O.; Udalcovs, A.; Schatz, R.; Guo, C.; Zhang, J.; Nordwall, F.; Engenhardt, K.M.; et al. Nonlinearity-aware 200Gbit/s DMT transmission for C-band short-reach optical interconnects with a single packaged electro-absorption modulated laser. Opt. Lett. 2018, 43, 182-185. [CrossRef] [PubMed]

35. Ozolins, O.; Zhang, L.; Udalcovs, A.; Louchet, H.; Dippon, T.; Gruen, M.; Pang, X.; Schatz, R.; Westergren, U.; Xiao, S.; et al. $300+$ Gbps short-reach optical communications. In Proceedings of the 2020 Conference on Lasers and Electro-Optics (CLEO), Washington, DC, USA, 10-15 May 2020; pp. 1-2.

36. Zhang, L.; Chen, J.; Udalcovs, A.; Pang, X.; Schatz, R.; Westergren, U.; Popov, S.; Xiao, S.; Ozolins, O. Kernel affine projection for nonlinearity tolerant optical short reach systems. IEEE Trans. Commun. 2020, 68, 6403-6412. [CrossRef]

37. Spyropoulou, M.; Kanakis, G.; Jiao, Y.; Stabile, R.; Calabretta, N.; Williams, K.; Dupuy, J.-Y.; Konczykowska, A.; Schatz, R.; Ozolins, O.; et al. Towards 1.6T datacentre interconnect technologies: The TWILIGHT perspective. J. Phys. Photonics 2020, 2, 041002. [CrossRef]

38. Zhou, X.; Urata, R.; Liu, H. Beyond $1 \mathrm{~Tb} / \mathrm{s}$ intra-data center interconnect technology: IM-DD OR coherent? J. Lightwave Technol. 2020, 38, 475-484. [CrossRef]

39. Chacinski, M.; Westergren, U.; Stoltz, B.; Thylen, L.; Schatz, R.; Hammerfeldt, S. Monolithically integrated 100 GHz DFB-TWEAM. J. Lightwave Technol. 2009, 27, 3410-3415. [CrossRef] 
40. Ozolins, O.; Pang, X.; Olmedo, M.I.; Kakkar, A.; Udalcovs, A.; Gaiarin, S.; Navarro, J.R.; Engenhardt, K.M.; Asyngier, T.; Schatz, R.; et al. $100 \mathrm{GHz}$ externally modulated laser for optical interconnects. J. Lightwave Technol. 2017, 35, 1174-1179. [CrossRef]

41. Matsui, Y.; Schatz, R.; Che, D.; Khan, F.; Kwakernaak, M.; Sudo, T. Low-chirp isolator-free 65-GHz-bandwidth directly modulated lasers. Nat. Photonics 2021, 15, 59-63. [CrossRef]

42. Yamaoka, S.; Diamantopoulos, N.-P.; Nishi, H.; Nakao, R.; Fujii, T.; Takeda, K.; Hiraki, T.; Tsurugaya, T.; Kanazawa, S.; Tanobe, H.; et al. Directly modulated membrane lasers with $108 \mathrm{GHz}$ bandwidth on a high-thermal-conductivity silicon carbide substrate. Nat. Photonics 2021, 15, 28-35. [CrossRef]

43. Chen, X.; Chandrasekhar, S.; Cho, J.; Winzer, P. Single-wavelength and single-photodiode entropy-loaded 554-Gb/s transmission over 22-km SMF. In Proceedings of the 2019 Optical Fiber Communications Conference and Exhibition (OFC), San Diego, CA, USA, 3-7 March 2019; pp. 1-3.

44. Yamazaki, H.; Nagatani, M.; Wakita, H.; Nakamura, M.; Kanazawa, S.; Ida, M.; Hashimoto, T.; Nosaka, H.; Miyamoto, Y. 160-GBd (320-Gb/s) PAM4 transmission using 97-GHz bandwidth analog multiplexer. IEEE Photonics Technol. Lett. 2018, 30, 1749-1751. [CrossRef]

45. Nagatani, M.; Wakita, H.; Jyo, T.; Mutoh, M.; Ida, M.; Voinigescu, S.P.; Nosaka, H. A 256-Gbps PAM-4 signal generator IC in 0.25 $\mu \mathrm{m}$ InP DHBT technology. In Proceedings of the 2018 IEEE BiCMOS and Compound Semiconductor Integrated Circuits and Technology Symposium (BCICTS), San Diego, CA, USA, 15-17 October 2018; pp. 28-31.

46. Baeuerle, B.; Heni, W.; Hoessbacher, C.; Fedoryshyn, Y.; Josten, A.; Haffner, C.; Watanabe, T.; Uhl, C.; Hettrich, H.; Elder, D.L.; et al. Reduced equalization needs of $100 \mathrm{GHz}$ bandwidth plasmonic modulators. J. Lightwave Technol. 2019, 37, 2050-2057. [CrossRef]

47. Buchali, F.; Schuh, K.; Le, S.T.; Du, X.; Grözing, M.; Berroth, M. A SiGe HBT BiCMOS 1-to-4 ADC frontend supporting 100 GBaud PAM4 reception at $14 \mathrm{GHz}$ digitizer bandwidth. In Proceedings of the 2019 Optical Fiber Communications Conference and Exhibition (OFC), San Diego, CA, USA, 3-7 March 2019; pp. 1-3.

48. Driad, R.; Makon, R.E.; Hurm, V.; Schneider, K.; Benkhelifa, F.; Losch, R.; Rosenzweig, J. In InP DHBT-based ICs for 100 Gbit/s data transmission. In Proceedings of the 2008 20th International Conference on Indium Phosphide and Related Materials, Versailles, France, 25-29 May 2008; pp. 1-4.

49. Jian, Y.; Pfister, H.D.; Narayanan, K.R.; Raghu, R.; Mazahreh, R. In Iterative hard-decision decoding of braided BCH codes for high-speed optical communication. In Proceedings of the 2013 IEEE Global Communications Conference (GLOBECOM), Atlanta, GA, USA, 9-13 December 2013; pp. 2376-2381.

50. Cvijetic, N.; Tanaka, A.; Ji, P.N.; Murakami, S.; Sethuraman, K.; Ting, W. First OpenFlow-based software-defined $\lambda$-flow architecture for flex-grid OFDMA mobile backhaul over passive optical networks with filterless direct detection ONUs. In Proceedings of the 2013 Optical Fiber Communication Conference and Exposition and the National Fiber Optic Engineers Conference (OFC/NFOEC), Anaheim, CA, USA, 17-21 March 2013; pp. 1-3.

51. GitHub. Available online: Github.com/dtu-dsp/Robochameleon (accessed on 2 February 2021). 